\title{
Effects of Rhizophagus intraradices on Plant Growth and the Composition of Microbial Communities in the Roots of Continuous Cropping Soybean at Maturity
}

\author{
Wei-Guang Jie ${ }^{+}(\mathbb{D})$, Yan-Xuan Yao ${ }^{\dagger}, \mathrm{Na}$ Guo ${ }^{*}$, Ying-Zhi Zhang and Wei Qiao \\ Department of Food and Environment Engineering, Heilongjiang East University, Harbin 150066, China; \\ jieweiguang2007@126.com (W.-G.J.); yaoy_xuan@126.com (Y.-X.Y.); yingzhizhang66@163.com (Y.-Z.Z.); \\ wonderjoe@126.com (W.Q.) \\ * Correspondence: guona0329@126.com \\ + Indicates the authors who contributed equally to this study.
}

Citation: Jie, W.-G.; Yao, Y.-X.; Guo, N.; Zhang, Y.-Z.; Qiao, W. Effects of Rhizophagus intraradices on Plant Growth and the Composition of Microbial Communities in the Roots of Continuous Cropping Soybean at Maturity. Sustainability 2021, 13, 6623. https://doi.org/10.3390/su13126623

Academic Editor: Sean Clark

Received: 19 April 2021

Accepted: 16 May 2021

Published: 10 June 2021

Publisher's Note: MDPI stays neutral with regard to jurisdictional claims in published maps and institutional affiliations.

Copyright: (c) 2021 by the authors. Licensee MDPI, Basel, Switzerland. This article is an open access article distributed under the terms and conditions of the Creative Commons Attribution (CC BY) license (https:/ / creativecommons.org/licenses/by/ $4.0 /)$.

\begin{abstract}
Soybean is the major food and oil crop in the world. However, soybean continuous cropping can significantly reduce soybean yield. In this study, the effects of Rhizophagus intraradices on soybean growth and the composition of microbial communities in soybean roots under different continuous cropping regimes were investigated at maturity. The results showed that the mycorrhizal colonization rate was affected by $R$. intraradices and soybean continuous cropping. The mycorrhizal colonization rate was the highest in the inoculated soybean plants under 1 year of continuous cropping. Inoculation of $R$. intraradices significantly increased soybean plant growth. The greatest biomass parameters were obtained from the soybean plants inoculated with $R$. intraradices under 0 years of continuous cropping. Bacterial diversity was decreased by soybean continuous cropping, while the opposite result occurred for fungal diversity. Moreover, inoculation of $R$. intraradices could increase and decrease the diversity of bacteria and fungi in soybean roots, respectively. It also indicated that $R$. intraradices and soybean continuous cropping had significant effects on the composition of microbial communities in soybean roots. Proteobacteria and Ascomycota were the most dominant bacterial and fungal phylum in all samples, respectively. It would contribute to developing a biocontrol strategy to alleviate the soybean continuous cropping obstacles.
\end{abstract}

Keywords: arbuscular mycorrhizal fungi; microbial communities; soybean; continuous cropping; high-throughput sequencing

\section{Introduction}

Soybean is a major leguminous crop, which is rich in seed oil, protein, isoflavone, oligosaccharides, saponin, and minerals [1]. Soybean can form a symbiosis with N-fixing bacteria and arbuscular mycorrhizal (AM) fungi [2]. However, soybean production is often limited by a variety of abiotic and biotic factors, especially soybean continuous cropping [3]. Soybean continuous cropping may lead to yield decline, inhibit the growth of some beneficial microbes, enrich the growth of some pathogenic microbes, and ultimately lead to soil degradation $[4,5]$.

AM fungi are oligotrophic microbes, which can colonize more than $90 \%$ of terrestrial plants, including rice, wheat, and soybean [6]. AM fungi can help plants with the uptake of nutrients and better cope with a variety of stress [7]. In addition, it has been reported that AM fungi can generally improve plant resistance to pathogens, alleviate symptoms and disease severity, and have a positive impact on plant growth [8]. AM fungi enhanced tomato disease resistance by priming systemic defense response [9]. AM fungi can protect their host plants from infection by soil pathogenic microorganisms such as fungi and bacteria [10-12]. Soybean plants inoculated with Funneliformis mosseae significantly reduced Fusarium oxysporum [13]. Inoculation of Rhizophagus intraradices reduced sudden death syndrome of soybean and relative F. virguliforme DNA quantities [14]. 
The application of microbial agents to plant rhizosphere has been proven to be a suitable strategy for plant growth and soil remediation. Our previous research has demonstrated the effects of $F$. mosseae on soybean growth and the composition of microbial communities in continuous cropping soybean roots $[15,16]$. Furthermore, $R$. intraradices were isolated from the rhizosphere soil of continuous cropping soybean by our research group. However, the effects of $R$. intraradices on the composition of microbial communities in continuous cropping soybean roots at maturity have never been reported. The present study was designed to examine soybean plant responses to inoculation of $R$. intraradices and continuous cropping regimes. It investigated (1) whether $R$. intraradices could exert positive effects on soybean growth under different continuous cropping regimes, (2) whether $R$. intraradices could impact the diversity, richness, and composition of microbial communities in the continuous cropping soybean roots. Therefore, the aim was to develop and apply a biocontrol strategy, in which $R$. intraradices was used to alleviate the soybean continuous cropping obstacles.

\section{Materials and Methods}

\subsection{Plant Materials}

Soybean (Glycine max L.) cv. Heinong 48 (HN48) that has been widely planted in the Heilongjiang Province of China was used in this study. It has an average fat and protein contents of $19.50 \%$ and $45.23 \%$, respectively.

\subsection{Arbuscular Mycorrhizal Inocula}

The AM fungus Rhizophagus intraradices were isolated from the rhizosphere soil of continuous cropping soybean by our research group. For mass production of $R$. intraradices, spores were propagated in sterilized soil, river sand, and vermiculite cultured with alfalfa as a host plant for about 5 months in a greenhouse. AM inocula consisted of $R$. intraradices colonized roots, spores, hyphae, and substrate.

\subsection{Experimental Design}

The research was carried out in the experimental fields of Heilongjiang East University $\left(126^{\circ} 61^{\prime} \mathrm{E}, 45^{\circ} 66^{\prime} \mathrm{N}\right)$, Heilongjiang Province, China from May to October, 2019. A twofactor randomized block design was used in the experiment: continuous cropping regimes and AM fungal inoculation, maintaining three replications for each treatment. There were two continuous cropping regimes ( 0 and 1 year of continuous cropping for soybean) and two AM fungal treatments (non-inoculated and inoculated with $R$. intraradices). Twelve 20 $\times 20 \mathrm{~m}$ plots (four treatments $\times$ three replicates) with a $2 \mathrm{~m}$ buffer between each plot were set. A spacing of $50 \mathrm{~cm}$ between rows and plants was maintained.

\subsection{Plant Growth Conditions}

Soybean seeds were superficially disinfected according to Jie et al. [15]. Before sowing the soybean seeds in fields, the soil was inoculated with AM inocula (5 g) at a depth of $2-3 \mathrm{~cm}$ below each soybean seed. The crops were regularly irrigated with tap water throughout the growth period.

\subsection{Plant Harvest}

For each treatment, soybean plants were randomly uprooted 5 months after sowing (maturity). The roots, shoots, and seeds of soybean were randomly collected. The soybean roots were repeatedly washed under running water. Some of the root samples were used for the determination of AM colonization, fresh weight, and dry weight, and then the rest of the roots were used for DNA extraction. The shoots were used to measure stem girth, fresh weight, and dry weight. The seeds were used for the determination of 100-seed weight and seed yield per plant. The pods were used to measure pod number per plant. 


\subsection{Mycorrhizal Colonization and Soybean Growth Analysis}

The degree of mycorrhizal colonization was estimated according to Phillips and Hayman [17]. The effects of $R$. intraradices on soybean plant growth were assessed by plant height, stem girth, fresh and dry weight of soybean root and shoot, 100-seed weight, seed yield per plant, and pods per plant. Three groups of parallel experiments were carried out.

\subsection{Illumina Sequencing}

The total genomic DNA of root samples was extracted according to Long et al. [18]. V3-V4 regions of 16S rDNA were amplified using 335F (5'-CADACTCCTACGGGAGGC-3') and 769R ( $5^{\prime}$-ATCCTGTTTGMTMCCCVCRC-3') [19]. The fragment size of 16S rDNA V3V4 regions was about $400 \mathrm{bp}$. ITS1 region was amplified using ITS1F (5'-CTTGGTCATTTA GAGGAAGTAA-3') and ITS2 (5'-GCTGCGTTCTTCATCGATGC-3') [20]. The fragment size of ITS1 region was about $250 \mathrm{bp}$. The PCR reaction system $(50 \mu \mathrm{L})$ contained $\mathrm{ddH}_{2} \mathrm{O} 28.8 \mu \mathrm{L}$, $10 \times$ PCR buffer $10.0 \mu \mathrm{L}, 2.5 \mathrm{mM}$ dNTP mixture $5 \mu \mathrm{L}, 2.0 \mu \mathrm{L}$ of each $5 \mu \mathrm{M}$ primer, $1.5 \mathrm{U}$ Taq DNA polymerase $0.2 \mu \mathrm{L}$, and template DNA $2.0 \mu \mathrm{L}$. The PCR cycling conditions were as follows: $5 \mathrm{~min}$ at $95^{\circ} \mathrm{C}$, followed by 30 cycles $\left(95^{\circ} \mathrm{C}\right.$ for $30 \mathrm{~s}, 50{ }^{\circ} \mathrm{C}$ for $30 \mathrm{~s}$, and $72{ }^{\circ} \mathrm{C}$ for $40 \mathrm{~s}$ ), and a final extension at $72{ }^{\circ} \mathrm{C}$ for $7 \mathrm{~min}$. The target PCR products were purified with GeneJET Gel Extraction Kit (Thermo Scientific, Waltham, MA, USA), and quantified with QuantiFluor ${ }^{\mathrm{TM}}$-ST (Promega, Madison, WI, USA), and then pooled at equal concentrations. Sequencing libraries were generated using TruSeq DNA PCR-free Sample Preparation Kit (Illumina, San Diego, CA, USA). The library quality was assessed on the Qubit 2.0 Fluorometer (Thermo Scientific, Waltham, MA, USA) and Agilent Bioanalyzer 2100 system. The comparisons of the microbial communities in the roots of continuous cropping soybean at maturity were analyzed by Illumina HiSeq 2500 (BioMarker Technologies Co., Ltd., Beijing, China). To confirm the accuracy of the sequencing, each treatment was composed of three replicates.

\subsection{Processing of Sequencing Data}

The raw paired-end sequences were joined with FLASH v1.2.7 [21]. Quality filtering on the raw paired-end sequences was performed by QIIME v1.8.0 [22]. Chimera sequences were eliminated by UCHIME Algorithm [23]. High-quality sequences with a similarity $\geq 97 \%$ were clustered into one operational taxonomic unit (OTU) [24]. Each OTU was classified and identified based on a BLAST search against the UNITE reference database. Taxonomic alpha diversity was based on the diversity of microbial communities in different root samples, using the ACE and Chaol index that reflected the richness of the microbial communities and the Simpson and Shannon diversity index that took the uniformity of the microbial communities into account, was measured using Mothur v.1.30. The distributions of common and unique OTUs based on 97\% sequence similarities were shown in VENN diagrams. The composition of microbial communities was analyzed according to the abundance distribution of the classification unit between the root samples and two heat maps were drawn using R software v.3.1.3. All raw reads have been deposited into the National Center for Biotechnology Information (NCBI) Sequence Read Archive (SRA) database (Accession number SRP189268 and SRP189301).

\subsection{Statistical Analysis}

Data were assessed by analysis of variance (ANOVA) using SPSS 22.0 (SPSS Inc., Chicago, IL, USA). Analysis of Tukey's test was applied to evaluate significant differences between treatments $(p<0.05)$.

\section{Results}

\subsection{Mycorrhizal Colonization Assessment}

The mycorrhizal colonization rate of soybean roots inoculated with $R$. intraradices was significantly higher than that of the control soybean roots without $R$. intraradices inoculation under different continuous cropping regimes (Table 1). As shown in Table 1, 
the mycorrhizal colonization rate was positively affected by increasing continuous cropping regimes. The mycorrhizal colonization rate was positively affected by the inoculation of $R$. intraradices, soybean continuous cropping, and their interactions. It indicated that the mycorrhizal colonization rate was the highest $(73.68 \%)$ in the inoculated soybean plants under 1 year of continuous cropping, while the lowest value $(18.32 \%)$ was found in the non-inoculated soybean plants under 0 years of continuous cropping (Table 1 ).

Table 1. Colonization rate of soybean roots by AM fungi.

\begin{tabular}{ccccc}
\hline Index & Non0Y & In0Y & Non1Y & In1Y \\
\hline Colonization rate $(\%)$ & $18.32 \pm 1.34^{\mathrm{c}}$ & $70.77 \pm 1.35^{\mathrm{b}}$ & $19.25 \pm 1.28^{\mathrm{c}}$ & $73.68 \pm 0.94^{\mathrm{a}}$ \\
\hline
\end{tabular}

Note: Non represents non-inoculated with $R$. intraradices. In represents inoculated with $R$. intraradices. OY and $1 Y$ represent zero years and one year of continuous cropping, respectively. Different letters indicate significant differences from different treatments $(p<0.05)$.

\subsection{Effects on Soybean Plants Growth}

The increase of continuous cropping regimes negatively affected soybean plant growth. Compared with the growth parameters of soybean plants under 0 years of continuous cropping, lower biomass parameters were observed under 1 year of continuous cropping (Table 2). Moreover, the obtained results showed that inoculation of $R$. intraradices significantly increased the plant height, stem girth, fresh and dry weight of root and shoot, 100-seed weight, seed yield per plant, and pods per plant compared with the corresponding control soybean plants. AM fungi inoculation increased (at least 7.99\%) the plant height, compared to non-inoculated soybean plants under different continuous cropping regimes. The variation of other biomass parameters was similar to that of plant height. The greatest biomass parameters were obtained from soybean plants inoculated with $R$. intraradices under 0 years of continuous cropping.

Table 2. Soybean biomass under different treatments.

\begin{tabular}{|c|c|c|c|c|c|c|c|c|c|}
\hline Treatments & $\begin{array}{l}\text { Plant Height } \\
\text { (cm) }\end{array}$ & $\begin{array}{l}\text { Stem Girth } \\
(\mathrm{cm})\end{array}$ & $\begin{array}{l}\text { Root Fresh } \\
\text { Weight (g) }\end{array}$ & $\begin{array}{c}\text { Root Dry } \\
\text { Weight (g) }\end{array}$ & $\begin{array}{l}\text { Shoot Fresh } \\
\text { Weight (g) }\end{array}$ & $\begin{array}{l}\text { Shoot Dry } \\
\text { Weight (g) }\end{array}$ & $\begin{array}{l}\text { 100-Seed } \\
\text { Weight (g) }\end{array}$ & $\begin{array}{c}\text { Seed-Yield } \\
\text { per Plant (g) }\end{array}$ & $\begin{array}{l}\text { Pods per } \\
\text { Plant }\end{array}$ \\
\hline Non0Y & $82.88 \pm 1.17^{b}$ & $1.00 \pm 0.05^{b}$ & $11.10 \pm 0.90^{b}$ & $3.40 \pm 0.39^{b}$ & $\begin{array}{c}100.69 \pm \\
1.74^{\mathrm{b}}\end{array}$ & $25.30 \pm 0.84^{b}$ & $24.64 \pm 1.21^{b}$ & $\begin{array}{c}22.55 \pm \\
0.94^{\mathrm{b}}\end{array}$ & $66.85 \pm 2.27^{b}$ \\
\hline In0Y & $89.50 \pm 1.76^{\mathrm{a}}$ & $1.14 \pm 0.06^{\mathrm{a}}$ & $16.43 \pm 0.73^{\mathrm{a}}$ & $4.39 \pm 0.38^{\mathrm{a}}$ & $\begin{array}{c}113.69 \pm \\
1.66^{\mathrm{a}}\end{array}$ & $30.90 \pm 1.23^{\mathrm{a}}$ & $26.94 \pm 1.01^{\mathrm{a}}$ & $\begin{array}{c}25.82 \pm \\
1.48^{\mathrm{a}}\end{array}$ & $78.51 \pm 1.03^{\mathrm{a}}$ \\
\hline Non1 Y & $74.01 \pm 1.18^{c}$ & $0.84 \pm 0.06^{c}$ & $8.38 \pm 0.72^{c}$ & $2.28 \pm 0.34^{c}$ & $81.03 \pm 1.24^{c}$ & $20.53 \pm 0.68^{c}$ & $\begin{array}{r}19.48 \pm \\
0.63^{\mathrm{d}}\end{array}$ & $\begin{array}{r}17.79 \pm \\
1.01^{\mathrm{d}}\end{array}$ & $\begin{array}{c}50.08 \pm \\
2.15^{\mathrm{d}}\end{array}$ \\
\hline In1Y & $84.46 \pm 1.23^{b}$ & $0.99 \pm 0.05^{b}$ & $11.35 \pm 1.01^{b}$ & $3.45 \pm 0.19^{b}$ & $99.36 \pm 2.24^{b}$ & $25.76 \pm 1.02^{b}$ & $21.40 \pm 1.16^{c}$ & $\begin{array}{r}19.77^{ \pm} \\
1.21^{\mathrm{c}}\end{array}$ & $59.27 \pm 1.60^{\circ}$ \\
\hline
\end{tabular}

Note: Non represents non-inoculated with $R$. intraradices. In represents inoculated with $R$. intraradices. $0 \mathrm{Y}$ and $1 Y$ represent zero years and one year of continuous cropping, respectively. Different letters indicate significant differences from different treatments $(p<0.05)$.

\subsection{Diversity and Abundance of Microbes in the Roots of Continuous Cropping Soybean}

A total of 653,744 and 930,788 sequences with an average of 163,436 and 232,697 high-quality bacterial and fungal sequences were obtained from each of the 4 samples, respectively. The diversity of bacteria and fungi in the roots of continuous cropping soybean showed a similar trend (Table 3). These bacterial and fungal sequences clustered into 649 and 1104 OTUs at a 97\% similarity level, respectively. The Good's coverages of these 8 libraries were greater than 0.999 (Table 3). For the bacterial communities, the Chao1 indexes of the 4 samples were $487.28-553.56$. The Shannon indexes showed variations of 2.8138-4.0754 in the 4 samples. For the fungal communities, the Chao1 indexes of the 4 samples were 543.43-595.86. The Shannon indexes showed variations of 4.29104.7948 in the 4 samples. The relatively low Chao1 and Shannon indexes indicated that the microbial diversity in the roots of continuous cropping soybean was low. Furthermore, for the bacterial communities, the Simpson index was the lowest in In0YRB, while the Ace index was the opposite. For the fungal communities, the Simpson index was the lowest in Non1YRF, and the Ace index was also the highest in Non1YRF. The results showed that 
the bacterial diversity levels in the roots of continuous cropping soybean under 0 years of continuous cropping were higher than those under 1 year of continuous cropping, while the opposite result occurred for the fungal diversity levels. In addition, the results showed that inoculation of $R$. intraradices could increase the diversity of bacteria and decrease the diversity of fungi in soybean roots.

Table 3. Diversity indices of bacteria and fungi in different samples.

\begin{tabular}{|c|c|c|c|c|c|c|}
\hline Sample ID & OTU & ACE & Chao1 & Simpson & Shannon & Coverage \\
\hline Non0YRB & $437 \pm 89^{a b}$ & $503.52 \pm 22.88^{a b}$ & $505.65 \pm 31.89^{a b}$ & $0.1033 \pm 0.0824^{a}$ & $3.5752 \pm 0.5533^{a}$ & $0.9998 \pm 0.0001^{a}$ \\
\hline In0YRB & $514 \pm 12^{a}$ & $539.35 \pm 18.87^{a}$ & $553.56 \pm 30.73^{a}$ & $0.0758 \pm 0.0287^{a}$ & $4.0754 \pm 0.1404^{a}$ & $0.9994 \pm 0.0003^{a}$ \\
\hline Non1YRB & $395 \pm 50^{b}$ & $461.75 \pm 14.39^{b}$ & $487.28 \pm 12.97^{b}$ & $0.2637 \pm 0.1951^{a}$ & $2.8138 \pm 1.1539^{a}$ & $0.9995 \pm 0.0004^{a}$ \\
\hline In1YRB & $451 \pm 53^{a b}$ & $496.19 \pm 44.30^{\mathrm{ab}}$ & $499.93 \pm 39.22 \mathrm{ab}$ & $0.1279 \pm 0.0966^{\mathrm{a}}$ & $3.2188 \pm 0.8709^{a}$ & $0.9998 \pm 0.0001^{a}$ \\
\hline Non0YRF & $537 \pm 10^{a}$ & $544.35 \pm 12.82^{a}$ & $551.15 \pm 18.35^{a}$ & $0.0271 \pm 0.0017^{\mathrm{a}}$ & $4.6749 \pm 0.0890^{\mathrm{a}}$ & $0.9997 \pm 0.0001^{a}$ \\
\hline In0YRF & $579 \pm 7^{a}$ & $500.65 \pm 17.55^{a}$ & $543.43 \pm 55.57^{a}$ & $0.0501 \pm 0.0079^{\mathrm{a}}$ & $4.2910 \pm 0.0513^{\mathrm{a}}$ & $0.9997 \pm 0.0001$ \\
\hline Non1YRF & $564 \pm 86^{a}$ & $588.18 \pm 5.64^{\mathrm{a}}$ & $595.86 \pm 12.28^{a}$ & $0.0225 \pm 0.0052^{\mathrm{a}}$ & $4.7948 \pm 0.1975^{\mathrm{a}}$ & $0.9997 \pm 0.0001$ \\
\hline In1YRF & $493 \pm 18^{a}$ & $571.07 \pm 87.10^{a}$ & $586.95 \pm 74.99^{a}$ & $0.0257 \pm 0.0052^{\mathrm{a}}$ & $4.7346 \pm 0.1410^{\mathrm{a}}$ & $0.9997 \pm 0.0001^{a}$ \\
\hline
\end{tabular}

Note: Non represents non-inoculated with $R$. intraradices. In represents inoculated with $R$. intraradices. $0 \mathrm{Y}$ and $1 \mathrm{Y}$ represent zero years and one year of continuous cropping, respectively. RB represents bacteria in root samples. RF represents fungi in root samples. Different letters indicate significant differences from different treatments $(p<0.05)$.

The distribution of OTUs was evaluated using VENN diagrams (Figure 1). As shown in Figure 1, there were significant differences in the amount of shared OTUs among the four root samples. Consistent with the alpha diversity, there were more shared OTUs in the four root samples.

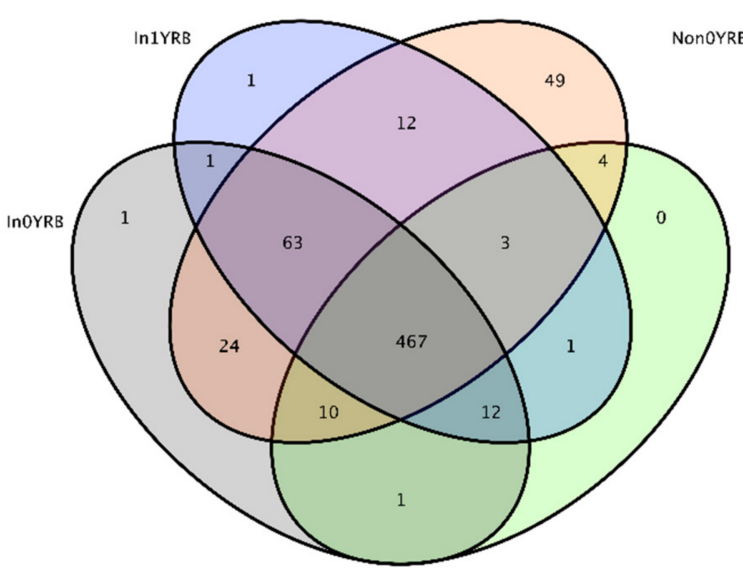

(a)

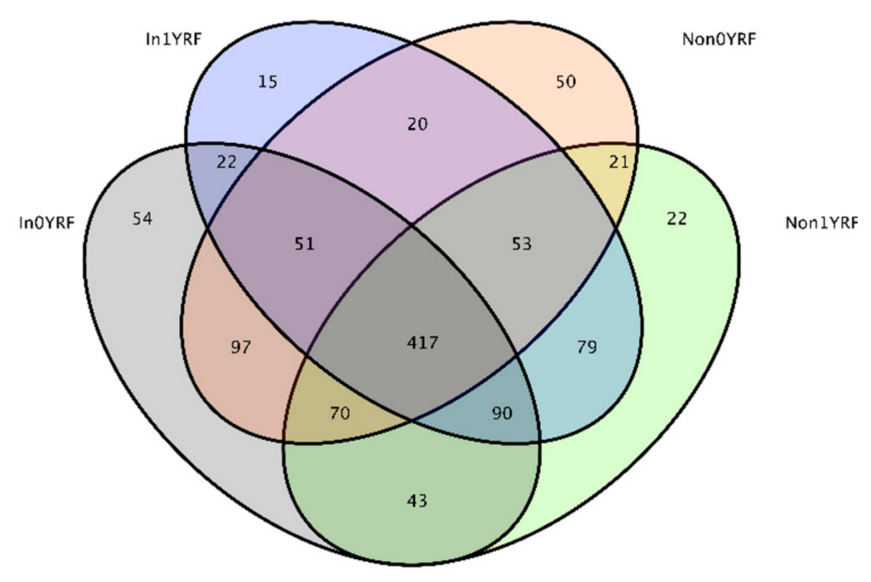

(b)

Figure 1. The VENN diagrams of the four root samples according to bacterial (a) and fungal (b) diversity. Note: Non represents non-inoculated with $R$. intraradices. In represents inoculated with $R$. intraradices. $0 Y$ and $1 Y$ represent zero years and one year of continuous cropping, respectively. RB represents bacteria in root samples. RF represents fungi in root samples.

\subsection{Effects of R. intraradices and Continuous Cropping Regimes on Bacterial Communities}

Considering taxa relative abundance, the number of bacterial sequences was identified. The most abundant bacterial phyla in the 4 samples were Proteobacteria, Bacteroidetes, Actinobacteria, Firmicutes, Patescibacteria, Gemmatimonadetes, Acidobacteria, Planctomycetes, Nitrospirae, and Chloroflexi (Figure 2a). As shown in Figure 2a, Proteobacteria (accounting for more than $60.24 \%$ of the totals) was the most dominant phylum in all samples. However, there were significant differences between the other most dominant phyla in the 4 samples. The relative abundance of these phyla varied significantly under the effects of $R$. intraradices and continuous cropping regimes. Firmicutes $(17.84 \%)$ and Bacteroidetes (14.00\%) were the second and third most dominant phylum in Non0YRB, 
respectively. Compared with Non0YRB, Bacteroidetes, and Actinobacteria were the second or third most dominant phyla and differed significantly in In0YRB, Non1YRB, and In1YRB. The relative abundance of Bacteroidetes increased from 5.25\% in In1YRB to $11.74 \%$ in InOYRB. The relative abundance of Actinobacteria increased from 3.67\% in In0YRB to $9.34 \%$ in In1YRB.

At the genus level, the most dominant genera in NonOYRB were Bradyrhizobium, Ensifer, uncultured_bacterium_f_Muribaculaceae, Lachnospiraceae_NK4A136_group, and Desulfovibrio with the relative abundances of $17.00 \%, 12.66 \%, 6.70 \%, 5.33 \%$, and $5.15 \%$, respectively (Figure 2b). Due to the inoculation, the relative abundances of Bradyrhizobium in In0YRB were higher than that in Non0YRB. The dominant genera in InOYRB were Bradyrhizobium (23.58\%), Novosphingobium (9.39\%), Ensifer (5.30\%), uncultured_bacterium_f_ Burkholderiaceae (5.12\%), and Pseudorhodoferax (3.97\%), which accounted for $47.36 \%$ of the total bacterial abundance. Bradyrhizobium and Ensifer were also observed as the most dominant genera in Non1YRB and In1YRB. However, the relative abundance of the dominant genera was also significantly different between Non1YRB and In1YRB. The relative abundance of Bradyrhizobium in Non1YRB $(26.19 \%)$ was much higher than that in In1YRB $(18.41 \%)$. The relative abundance of Ensifer in In1YRB increased to $43.67 \%$, whereas, that of Ensifer in Non1YRB decreased to $16.89 \%$. Furthermore, all samples except In1YRB (Ensifer was the most dominant genus) were characterized by a high relative abundance of Bradyrhizobium. The relative abundance of Ensifer in In1YRB was 8.24 times higher than that in InOYRB.

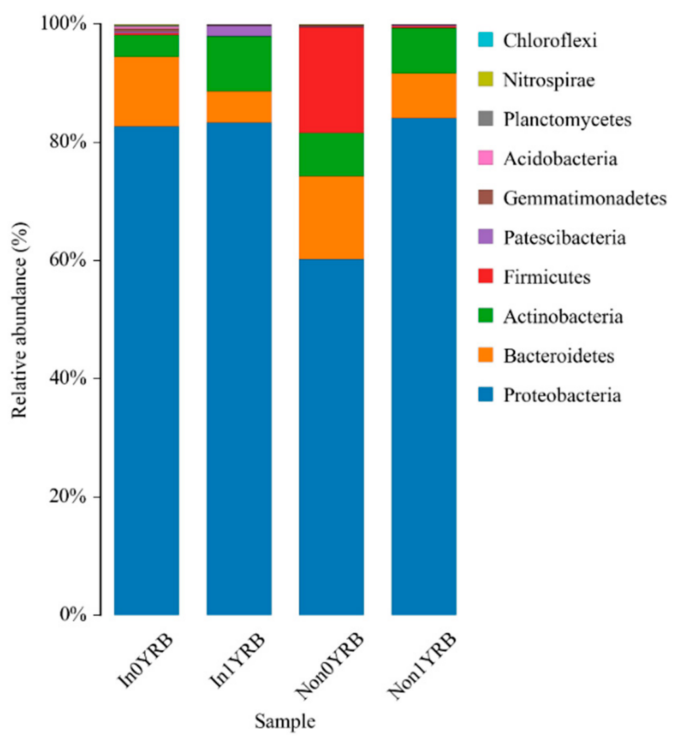

(a)

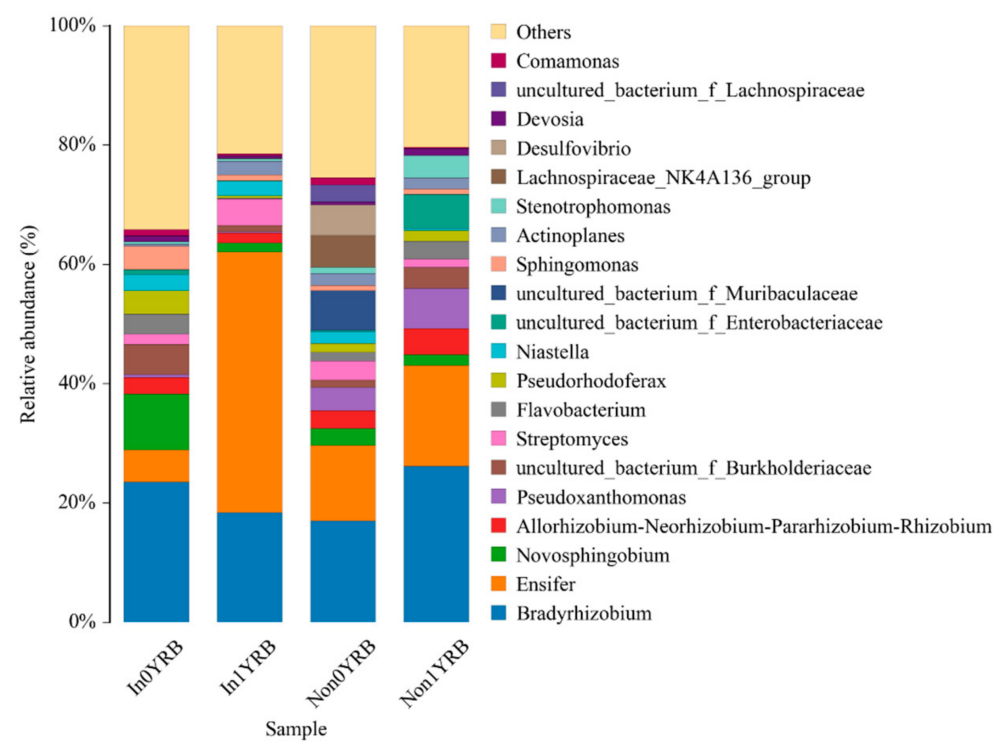

(b)

Figure 2. Composition of bacterial communities at the phylum (a) and genus (b) levels in soybean roots. Note: Non represents non-inoculated with $R$. intraradices. In represents inoculated with $R$. intraradices. $0 \mathrm{Y}$ and $1 \mathrm{Y}$ represent zero years and one year of continuous cropping, respectively. RB represents bacteria in root samples.

The top 100 OTUs assemblage also clearly separated the 4 samples into the following 2 clusters: In0YRB did not cluster with other samples; Non0YRB, Non1YRB, and In1YRB clustered together, suggesting their similar core function in shaping the composition of bacterial communities (Figure 3). Furthermore, it showed that the dominant genera and their relative abundance of the 4 samples were significantly affected by the inoculation of $R$. intraradices and continuous cropping regimes. 


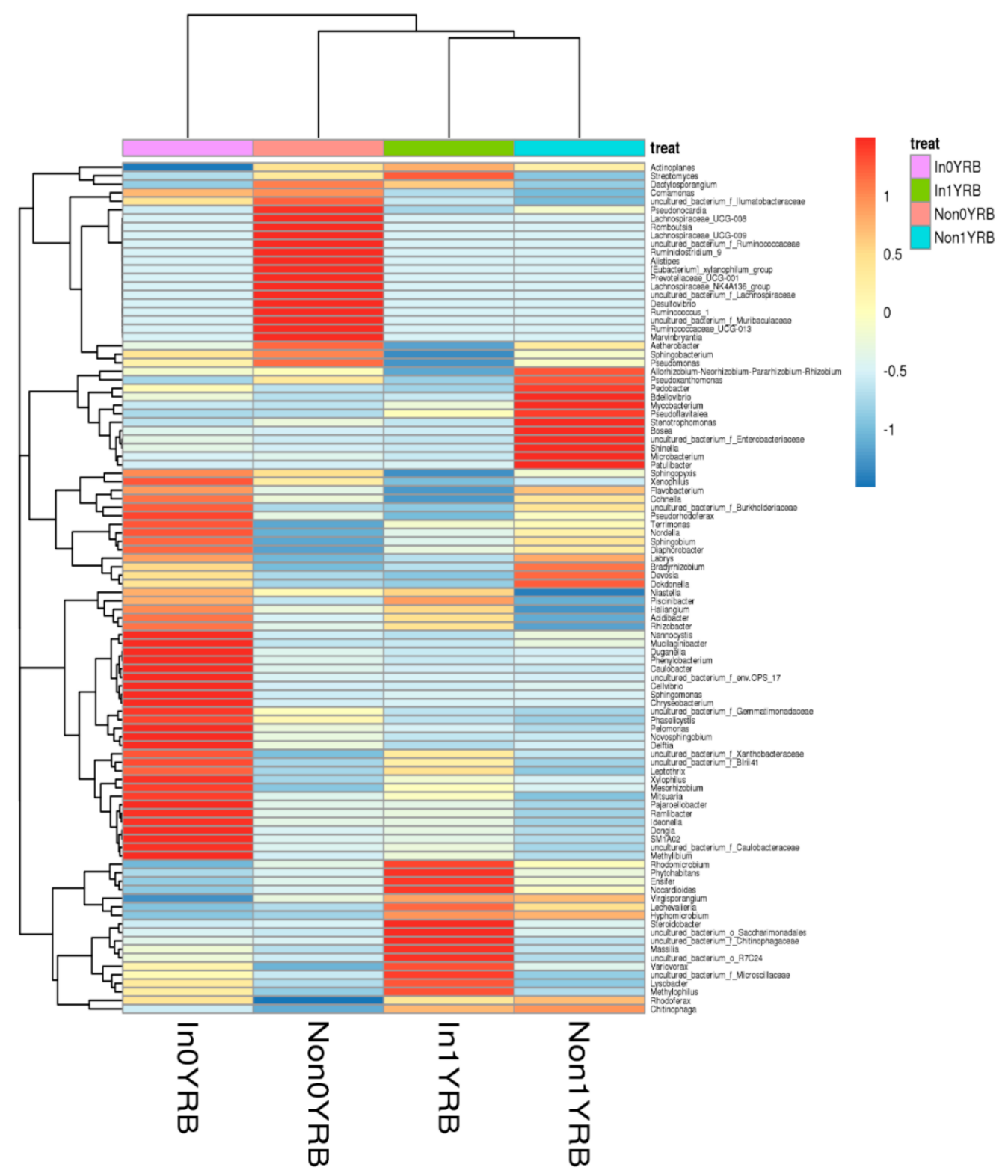

Figure 3. Heat map of the 100 most abundant bacterial genera in the different samples. Note: Non represents non-inoculated with $R$. intraradices. In represents inoculated with $R$. intraradices. $0 Y$ and $1 Y$ represent zero years and one year of continuous cropping, respectively. RB represents bacteria in root samples.

\subsection{Effects of R. intraradices and Continuous Cropping Regimes on Fungal Communities}

Taxonomic analysis showed the most abundant fungal phyla in the 4 samples. At the phylum level, 9 identified phyla were discovered and Ascomycota was the most abundant phylum in the 4 samples (Figure 4a). The relative abundance of Ascomycota accounted for more than $55.91 \%$ of the total amount in the 4 samples. Basidiomycota was the second dominant phylum in the 4 samples. Interestingly, the relative abundance of Basidiomycota in the roots under 1 year of continuous cropping for soybean was significantly lower than that in the roots under 0 years of continuous cropping for soybean. Mortierellomycota and Glomeromycota were the third and fourth dominant phylum in all the samples except In0YRF, respectively. However, Glomeromycota and Mortierellomycota were the third and fourth dominant phylum in In0YRF, respectively. Furthermore, the relative abundance of the other most dominant phyla varied significantly under the effects of $R$. intraradices and continuous cropping regimes. 
At the genus level, the dominant genera in Non1YRF were Fusarium $(9.91 \%)$, Plectosphaerella (9.22\%), Mortierella (5.44\%), Fusicolla (2.58\%), Penicillium (2.51\%), Ilyonectria (2.21\%), Humicola (2.11\%), Tausonia (1.69\%), Solicoccozyma (1.17\%), and Stagonosporopsis $(1.05 \%)$, which accounted for $37.89 \%$ of the total fungal abundance (Figure $4 \mathrm{~b})$. As shown in Figure $4 \mathrm{~b}$, the relative abundance of Fusarium in Non1YRF was higher than the other 3 samples. Furthermore, Holocotylon (1.83\%), Cladosporium $(0.73 \%)$, Preussia $(0.73 \%)$, Chaetomium $(0.56 \%)$, Aspergillus $(0.38 \%)$, Lectera $(0.38 \%)$, Tetracladium $(0.32 \%)$, Didymella $(0.29 \%)$, Colletotrichum $(0.22 \%)$, and Metacordyceps $(0.02 \%)$ were also detected in Non1YRF. However, Metacordyceps was not detected in In1YRF. The most dominant genera were significantly different among the 4 samples. Tausonia (20.10\%), Fusarium (9.91\%), Plectosphaerella (11.06\%), and Chaetomium (7.01\%) were the most dominant genera in Non0YRF, Non1YRF, In0YRF, and In1YRF, respectively. The relative abundance of Chaetomium and Tausonia decreased significantly, remaining at around $0.28 \%$ and $1.69 \%$ in InOYRF and Non1YRF, respectively. It indicated that inoculation and continuous cropping had significant effects on the composition of fungal communities in soybean roots in this study.

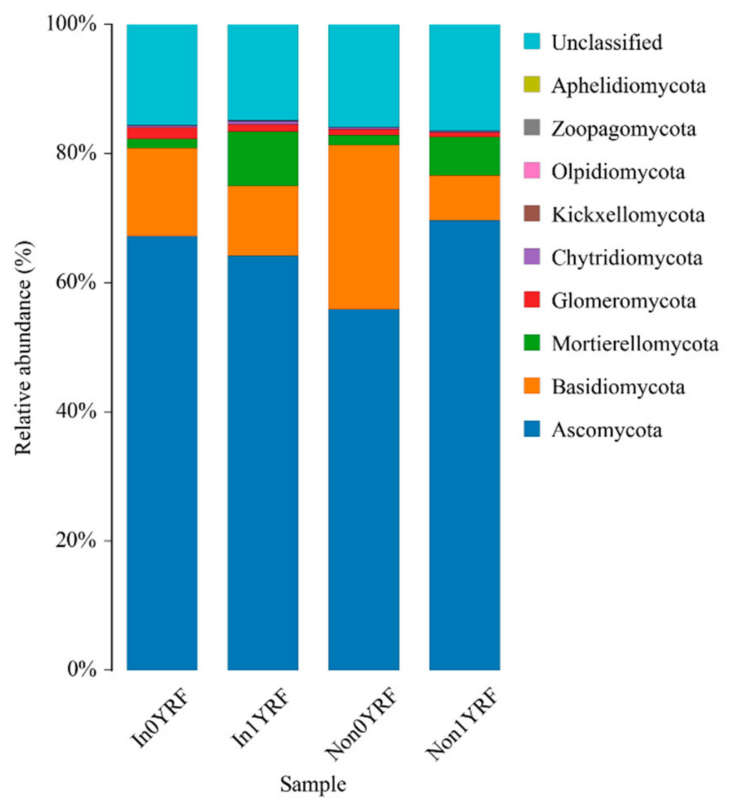

(a)

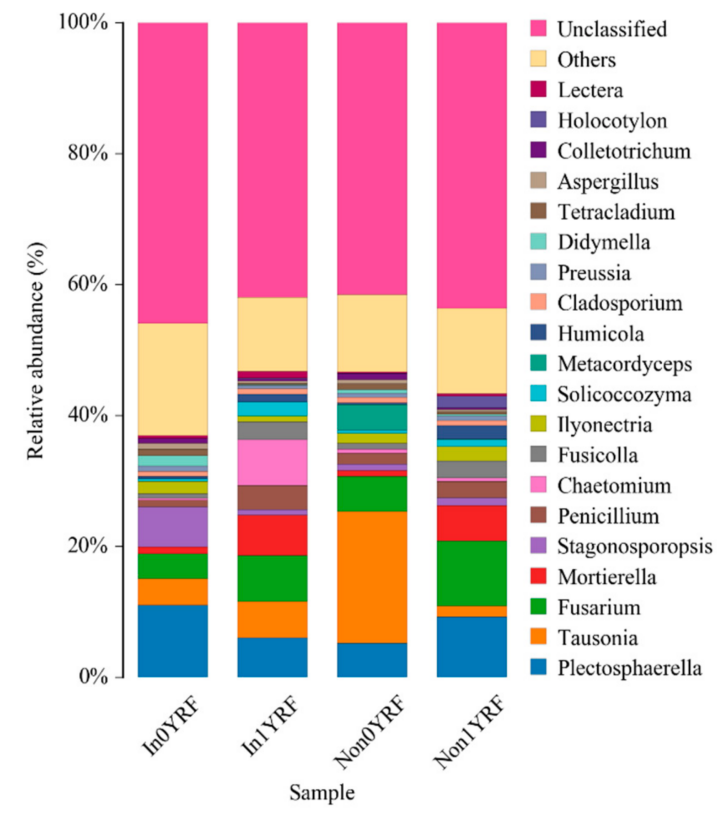

(b)

Figure 4. The composition of fungal communities at the phylum (a) and genus (b) levels in soybean roots. Note: Non represents non-inoculated with $R$. intraradices. In represents inoculated with $R$. intraradices. $0 \mathrm{Y}$ and $1 \mathrm{Y}$ represent zero years and one year of continuous cropping, respectively. RF represents fungi in root samples.

According to the heat map diagram of the fungal communities at the genus level, the 4 samples were divided into two clusters: Non0YRF and InOYRF clustered together; Non1YRF and In1YRF clustered together, indicating that the fungal communities were similar in the 2 samples (Figure 5). The results were consistent with the composition of fungal communities at the genus level. Moreover, it also showed that both the inoculation of $R$. intraradices and continuous cropping regimes had significant effects on the dominant genera and their relative abundances in the 4 samples. 


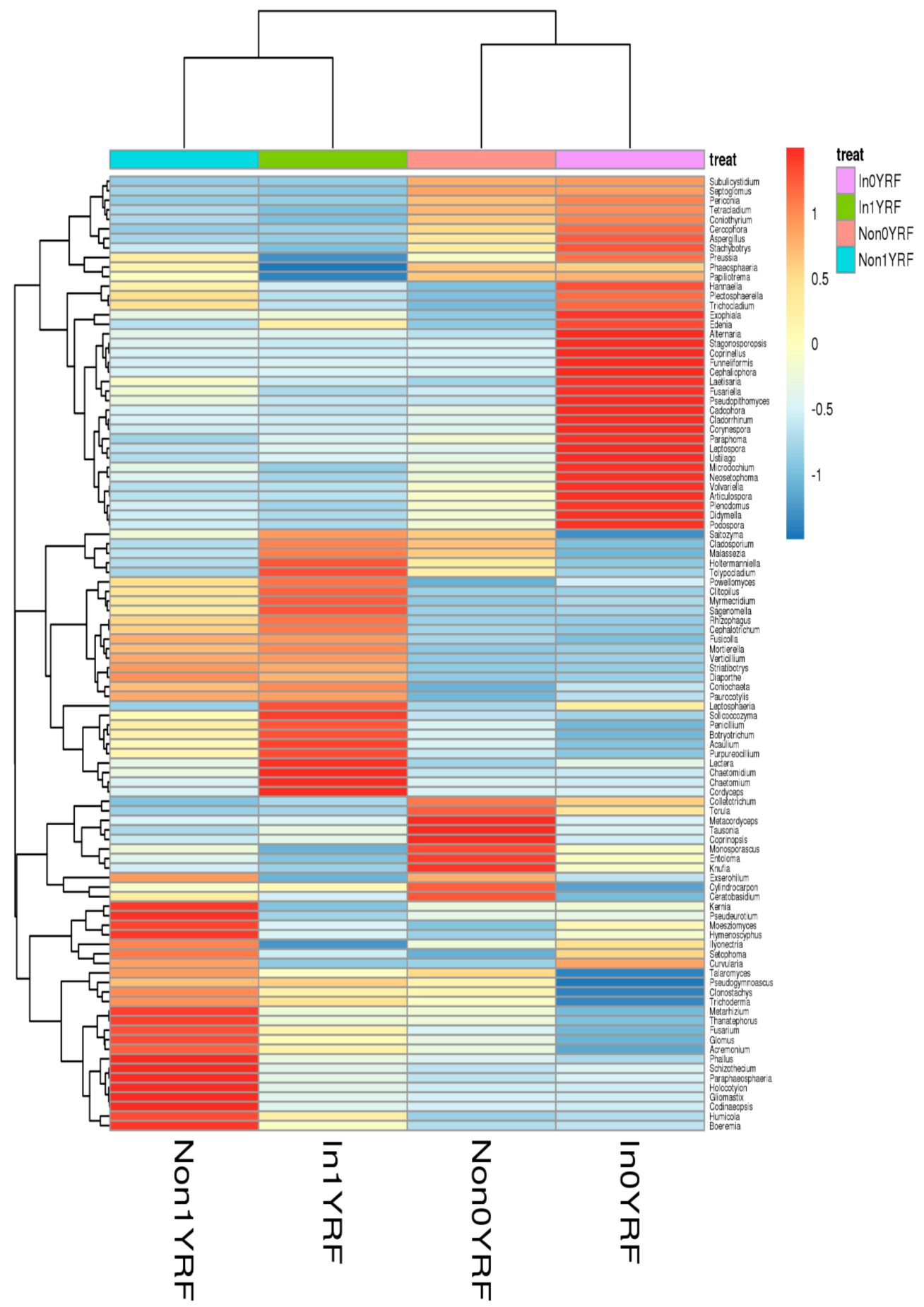

Figure 5. Heat map of the 100 most abundant fungal genera in the different samples. Note: Non represents non-inoculated with $R$. intraradices. In represents inoculated with $R$. intraradices. $0 Y$ and $1 Y$ represent zero years and one year of continuous cropping, respectively. RF represents fungi in root samples.

\section{Discussion}

In this study, a system involving soybean and the generalist AM fungus $R$. intraradices was established to examine the effects of mycorrhizal colonization and continuous cropping regimes on the growth parameters of soybean plants and the composition of microbial communities in continuous cropping soybean roots at maturity. This is the first demonstration that $R$. intraradices can directly alter the growth of soybean plants and the composition of microbial communities in soybean roots under continuous cropping conditions, contribut- 
ing to alleviate soybean continuous cropping obstacles by biological methods. Colonization or infection by some beneficial microorganisms initiates specific physiological states of plants $[25,26]$. The induced plants exhibit stronger and quicker induction of defense responses [27]. When AM fungi colonize plant roots, morphological changes occur inside the host plants, such as an increase of cell wall lignification, which may contribute to biological protection [28]. Mycorrhizal colonization is not only beneficial to plant nutrient absorption, but also to plant resistance to various abiotic stresses and pathogenic soil microorganisms including bacteria and fungi $[9,29]$. Although AM fungi have many benefits in agroecosystems, farmers are more willing to apply chemical fertilizers to improve crop yield for short-term economic benefits, especially in China. The application of chemical fertilizers in agricultural production can affect the relationship between pathogenic organisms and their hosts [30]. The results provided strong evidence for the ability of $R$. intraradices to improve soybean biomass. AM fungi promote plant growth by increasing the absorption of $\mathrm{P}$ and other nutrients [31]. AM fungal species and their specificity to host determine the formation of extracellular and intracellular hyphae, arbuscular mycorrhiza, and chlamydospores in soil [32]. In addition, there was an increase in plant height, stem girth, fresh and dry weight of root and shoot, 100-seed weight, seed yield per plant, and pods per plant that might be the result of nutrient uptake by the $R$. intraradices inoculated soybean plant roots. The feasibility of applying AM fungi to soils depends on several factors, including habitat niche validity, species compatibility, and competition with native fungi [33]. However, there has been little research focused on the effects of $R$. intraradices on both mycorrhizal colonization and the growth of soybean plants under continuous cropping conditions. In this study, mycorrhizal colonization and soybean growth were significantly affected by the inoculation of $R$. intraradices, indicating that $R$. intraradices had positive effects on these indexes. Furthermore, continuous cropping significantly increased mycorrhizal colonization in soybean at maturity (Table 1).

Artursson et al. [34] reported that the beneficial effects of AM fungi may be due to their interactions with rhizosphere microorganisms. Microbial interactions involving AM fungi and plant growth-promoting rhizosphere microorganisms, as well as AM fungi and rhizosphere indigenous microbial communities, can promote plant growth to a certain extent [35]. In this study, $R$. intraradices not only significantly increased mycorrhizal colonization and soybean growth, but also changed the composition of microbial communities in continuous cropping soybean roots at maturity. We found clear and significant differences in the composition of microbial communities between inoculated and non-inoculated soybean plants under different continuous cropping regimes. It may be mainly due to the different responses of rhizosphere microorganisms to root exudates caused by the inoculation of $R$. intraradices and soybean continuous cropping. Continuous cropping decreased the abundance and diversity of plant litter, which decreased the diversity of soil microorganisms [36]. In addition, it showed that soybean continuous cropping obviously decreased bacterial richness and diversity in both inoculated and non-inoculated soybean plants. We also found that the relative abundances of several bacterial and fungal phyla varied significantly under the effects of $R$. intraradices and continuous cropping regimes (Figures 2a and $4 \mathrm{a}$ ). Although there were differences between treatments, Proteobacteria was the most dominant bacterial phylum in the four samples. Ascomycota and Basidiomycota were the first and second most dominant fungal phylum in all samples, respectively. High-throughput sequencing technology can detect many secondary members of bacterial and fungal communities, many of which are not shown in the existing database. In this study, many unclassified phyla/genera were identified. The unclassified members of endophytic bacterial and fungal communities in soybean roots, indicating the great potential of these microorganisms for the development of beneficial microbial communities. The results showed that inoculation of $R$. intraradices could change the composition of microbial communities in continuous cropping soybean roots and improve the growth performance of soybean plants. Moreover, the results of this study would contribute to isolate and identify the beneficial endophytic bacteria and fungi in continuous cropping soybean. 


\section{Conclusions}

This work first demonstrated that $R$. intraradices can directly alter the growth of soybean plants and the composition of microbial communities in continuous cropping soybean roots. Mycorrhizal colonization and soybean growth were significantly increased by the inoculation of $R$. intraradices. However, fungal richness and diversity were increased by soybean continuous cropping, while the opposite result occurred for bacterial richness and diversity. Moreover, inoculation of $R$. intraradices could increase the diversity of bacteria and decrease the diversity of fungi in soybean roots. The relative abundances of several bacterial and fungal phyla varied significantly under the effects of $R$. intraradices and continuous cropping regimes. Proteobacteria and Ascomycota were the most dominant bacterial and fungal phylum in all samples, respectively. The purpose of this study was to develop and apply a biocontrol strategy in which $R$. intraradices was used to alleviate the soybean continuous cropping obstacles.

Author Contributions: Conceptualization, W.-G.J.; methodology, W.-G.J. and Y.-X.Y.; software, N.G.; validation, Y.-X.Y.; formal analysis, Y.-Z.Z. and W.Q.; investigation, W.-G.J. and Y.-X.Y.; writingoriginal draft preparation, W.-G.J.; writing-review and editing, W.-G.J. All authors have read and agreed to the published version of the manuscript.

Funding: This research was funded by the Natural Science Foundation of Heilongjiang Province, grant YQ2019C016.

Institutional Review Board Statement: Not applicable.

Informed Consent Statement: Not applicable.

Data Availability Statement: All the data produced here is available and can produced when required.

Acknowledgments: The authors are grateful to BioMarker Technologies Co., Ltd., Beijing, China for their excellent technical assistance.

Conflicts of Interest: The authors declare no conflict of interest.

\section{References}

1. Cui, G.J;; Ai, S.Y.; Chen, K.; Wang, X.R. Arbuscular mycorrhiza augments cadmium tolerance in soybean by altering accumulation and partitioning of nutrient elements, and related gene expression. Ecotox. Environ. Saf. 2019, 171, 231-239. [CrossRef] [PubMed]

2. Marro, N.; Cofré, N.; Grilli, G.; Alvarez, C.; Labuckas, D.; Maestri, D.; Urcelay, C. Soybean yield, protein content and oil quality in response to interaction of arbuscular mycorrhizal fungi and native microbial populations from mono- and rotation-cropped soils. Appl. Soil Ecol. 2020, 152, 103575. [CrossRef]

3. Liu, H.; Pan, F.J; Han, X.Z.; Song, F.B.; Zhang, Z.M.; Yan, J.; Xu, Y.L. A comprehensive analysis of the response of the fungal community structure to long-term continuous cropping in three typical upland crops. J. Integr. Agric. 2020, 19, 866-880. [CrossRef]

4. Liu, Z.X.; Liu, J.J.; Yu, Z.H.; Yao, Q.; Li, Y.S.; Liang, A.Z.; Zhang, W.; Mi, G.; Jin, J.; Liu, X.B.; et al. Long-term continuous cropping of soybean is comparable to crop rotation in mediating microbial abundance, diversity and community composition. Soil Till. Res. 2020, 197, 104503. [CrossRef]

5. Tian, L.; Shi, S.H.; Ma, L.N.; Tran, L.S.P.; Tian, X.J. Community structures of the rhizomicrobiomes of cultivated and wild soybeans in their continuous cropping. Microbiol. Res. 2020, 232, 126390. [CrossRef]

6. Zeng, H.L.; Zhong, W.; Tan, F.X.; Shu, Y.H.; Feng, Y.J.; Wang, J.W. The influence of Bt maize cultivation on communities of arbuscular mycorrhizal fungi revealed by MiSeq sequencing. Front Microbiol. 2019, 9, 3275. [CrossRef]

7. Rizzo, E.; Sherman, T.; Manosalva, P.; Gomez, S.K. Assessment of local and systemic changes in plant gene expression and aphid responses during potato interactions with arbuscular mycorrhizal fungi and potato aphids. Plants 2020, 9, 82. [CrossRef]

8. Spagnoletti, F.N.; Leiva, M.; Chiocchio, V.; Lavado, R.S. Phosphorus fertilization reduces the severity of charcoal rot (Macrophomina phaseolina) and the arbuscular mycorrhizal protection in soybean. J. Plant Nutr. Soil Sci. 2018, 181, 855-860. [CrossRef]

9. Song, Y.Y.; Chen, D.M.; Lu, K.; Sun, Z.X.; Zeng, R.S. Enhanced tomato disease resistance primed by arbuscular mycorrhizal fungus. Front Plant Sci. 2015, 6, 786. [CrossRef] [PubMed]

10. Nafady, N.A.; Hashem, M.; Hassan, E.A.; Ahmed, H.A.M.; Alamri, S.A. The combined effect of arbuscular mycorrhizae and plant-growth-promoting yeast improves sunflower defense against Macrophomina phaseolina diseases. Biol. Control 2019, 138, 104049. [CrossRef]

11. Aseel, D.G.; Rashad, Y.M.; Hammad, S.M. Arbuscular mycorrhizal fungi trigger transcriptional expression of flavonoid and chlorogenic acid biosynthetic pathways genes in tomato against tomato Mosaic virus. Sci. Rep. UK 2019, 9, 9692. [CrossRef] [PubMed] 
12. Dreher, D.; Baldermann, S.; Schreiner, M.; Hause, B. An arbuscular mycorrhizal fungus and a root pathogen induce different volatiles emitted by Medicago truncatula roots. J. Adv. Res. 2019, 19, 85-90. [CrossRef] [PubMed]

13. Jie, W.G.; Bai, L.; Yu, W.J.; Cai, B.Y. Analysis of interspecific relationships between Funneliformis mosseae and Fusarium oxysporum in the continuous cropping of soybean rhizosphere soil during the branching period. Biocontrol Sci. Technol. 2015, 25, 1036-1051. [CrossRef]

14. Pawlowski, M.L.; Hartman, G.L. Reduction of sudden death syndrome foliar symptoms and Fusarium virguliforme DNA in roots inoculated with Rhizophagus intraradices. Plant Dis. 2020, 104, 1415-1420. [CrossRef]

15. Jie, W.G.; Lin, J.X.; Guo, N.; Cai, B.Y.; Yan, X.F. Community composition of rhizosphere fungi as affected by Funneliformis mosseae in soybean continuous cropping soil during seedling period. Chil. J. Agric. Res. 2019, 79, 356-365. [CrossRef]

16. Jie, W.G.; Lin, J.X.; Guo, N.; Cai, B.Y.; Yan, X.F. Effects of Funneliformis mosseae on mycorrhizal colonization, plant growth and the composition of bacterial community in the rhizosphere of continuous cropping soybean at seedling stage. Int. J. Agric. Biol. 2019, 22, 1173-1180.

17. Phillips, J.M.; Hayman, D.S. Improved procedures for clearing roots and staining parasitic and cesicula-arbuscular mycorrhizal fungi for rapid, assessment of infection. Trans. Brit. Mycol. Soc. 1970, 55, 158-161. [CrossRef]

18. Long, L.K.; Yang, S.Z.; Yao, Q.; Zhu, H.H. DNA extraction from arbuscular mycorrhizal fungi and analysis by PCR-denaturing gradient gel electrophoresis. Mycosystema 2005, 24, 564-569.

19. Dorn-In, S.; Bassitta, R.; Schwaiger, K.; Bauer, J.; Holzel, C.S. Specific amplification of bacterial DNA by optimized so-called universal bacterial primers in samples rich of plant DNA. J. Microbiol. Meth. 2015, 113, 50-56. [CrossRef]

20. Smith, D.P.; Peay, K.G. Sequence depth, not PCR replication, improves ecological inference from next generation DNA sequencing. PLoS ONE 2014, 9, e90234. [CrossRef]

21. Magoc, T.; Salzberg, S.L. FLASH: Fast length adjustment of short reads to improve genome assemblies. Bioinformatics 2011, 27, 2957-2963. [CrossRef]

22. Caporaso, J.G.; Kuczynski, J.; Stombaugh, J.; Bittinger, K.; Bushman, F.D.; Costello, E.K. QIIME allows analysis of high-throughput community sequencing data. Nat. Methods 2010, 7, 335-336. [CrossRef] [PubMed]

23. Edgar, R.C.; Haas, B.J.; Quince, C.; Knight, R. UCHIME improves sensitivity and speed of chimera detection. Bioinformatics 2011, 27, 2194-2200. [CrossRef] [PubMed]

24. Armougom, F.; Raoult, D. Exploring microbial diversity using $16 \mathrm{~S}$ rRNA highthroughput methods. J. Comput. Sci. Syst. Biol. 2009, 2, 74-92. [CrossRef]

25. Hao, Z.P.; Fayolle, L.; van Tuinen, D.; Chatagnier, O.; Li, X.L. Local and systemic mycorrhiza-induced protection against the ectoparasitic nematode Xiphinema index involves priming of defence gene responses in grapevine. J. Exp. Biol. 2012, 63, 3657-3672. [CrossRef] [PubMed]

26. Aimé, S.; Alabouvette, C.; Steinberg, C.; Olivain, C. The endophytic strain Fusarium oxysporum Fo47: A good candidate for priming the defense responses in tomato roots. Mol. Plant Microbe Interact. 2013, 26, 918-926. [CrossRef]

27. Slaughter, A.; Daniela, X.; Flors, V.; Luna, E.; Hohn, B.; Brigitte, M.M. Descendants of primed Arabidopsis plants exhibit resistance to biotic stress. Plant Physiol. 2012, 158, 835-843. [CrossRef]

28. Al-Askar, A.A.; Rashad, Y.M. Arbuscular mycorrhizal fungi: A biocontrol agent against common. Plant Pathol. J. 2010, 9, 31-38. [CrossRef]

29. Sharma, I.P.; Sharma, A.K. Physiological and biochemical changes in tomato cultivar PT-3 with dual inoculation of mycorrhiza and PGPR against root-knot nematode. Symbiosis 2017, 71, 175-183. [CrossRef]

30. Veresoglou, S.D.; Barto, E.K.; Menexes, G.; Rillig, M.C. Fertilization affects severity of disease caused by fungal plant pathogens. Plant Pathol. 2013, 62, 961-969. [CrossRef]

31. Nwangburuka, C.C.; Olawuyi, O.J.; Oyekale, K.; Ogunwemimo, K.O.; Denton, O.; Daramola, D.S.; Awotade, D. Effect of Arbuscular mycorrhizal (AM), Poultry Manure (PM), NPK fertilizer and the combination of AM-PM on the Growth and Yield of Okra (Abelmoschus esculentus). Nat. Sci. 2012, 10, 9-16.

32. Abott, L.K.; Robson, A.D. Infectivity and effectiveness of five Endomycorrhizal fungi: Competition of indigenous fungi in field soils. Aust. J. Agric. Res. 1982, 32, 621-663. [CrossRef]

33. Verbruggen, E.; Heijden, M.G.; Rillig, M.C.; Kiers, E.T. Mycorrhizal fungal establishment in agricultural soils: Factors determining inoculation success. New Phytol. 2013, 197, 1104-1109. [CrossRef]

34. Artursson, V.; Finlay, R.D.; Jansson, J.K. Interactions between arbuscular mycorrhizal fungi and bacteria and their potential for stimulating plant growth. Environ. Microbiol. 2006, 8, 1-10. [CrossRef] [PubMed]

35. Rodríguez-Caballero, G.; Caravaca, F.; Fernández-González, A.J.; Alguacil, M.M.; Fernández-López, M.; Roldán, A. Arbuscular mycorrhizal fungi inoculation mediated changes in rhizosphere bacterial community structure while promoting revegetation in a semiarid ecosystem. Sci. Total Environ. 2017, 584, 838-848. [CrossRef] [PubMed]

36. Van der Heijden, M.G.A.; Bardgett, R.D.; van Straalen, N.M. The unseen majority: Soil microbes as drivers of plant diversity and productivity in terrestrial ecosystems. Ecol. Lett. 2008, 11, 296-310. [CrossRef] 